http://dx.doi.org/10.5392/IJoC.2013.9.4.086

\title{
Ambivalent Reading on the Story of the Colonialism in The Piano
}

\author{
Seung Hyun Park \\ School of Communications \\ Hallym University, Chunchon, Gangwon-do, 200-702, Korea \\ Jae Il Nam* \\ Dep. of Journalism and Mass Communication \\ Kyungpook University, Daegu City, Korea
}

\begin{abstract}
The Piano, directed by Jane Campion in 1993, became a sensational movie with a special theme focusing on gender and sexual identity, when it won Palme d'Or in the Cannes Film Festival at the same year. Most of the critics discuss the representation of Victorian sexual repression in the colonial setting. But the critical acclaim tends to view the existence of the Maori people and the colonial setting as the backdrop of the narrative, although this colonial background is constructed as a medium to accelerate the release of the repressed passion. Regarding the race issue as a compelling discourse that gets left out of "feminist" accounts, this paper analyzes The Piano, focusing on both how the story of colonialism is constituted in the film and how the film represents ambivalent images of the Maori people, the native of New Zealand.
\end{abstract}

Key words: The Piano, Jane Campion, Maori, race representation, gender identity

\section{INTRODUCTION}

In The Piano, the themes of gender and sexual identity are considered the most central elements of the narrative, as revealed in many film reviews and criticisms. Most of the critics focus on the release of Victorian sexual repression in the colonial setting and regard the film as a new mode of the female melodrama whose narrative concentrates on female character's active passion. The critical acclaim tends to view the existence of the Maori people and the colonial setting as the backdrop of the narrative, although this colonial background is constructed as a medium to accelerate the release of the repressed passion.

Lynda Dyson, who reads the film through the story of the colonialism, explains the depiction of the Maori and their nature as an act of "reconciliation" between the Maori people and the Pakeha, descendants of the European. For her, this reconciliation is realized as "a textual palliative for postcolonial anxieties generated by the contemporary struggle over the nation's past [1]." Dyson describes Baines (played by Harvey Keitel) as "the man who has already 'gone native'" and comprehends indigenous people as "noble savages" and "the keepers of spiritual and authentic values [2]." How does the

* Corresponding author,Email: commat@knu.ac.kr Manuscript received Sep. 30, 2013; revised Dec. 11, 2013; accepted Dec. 20, 2013 film describe the Maori as the keepers of spiritual and authentic values? However, she does not mention what are "spiritual and authentic values" as well as how the Maori are represented as the keepers of these values.

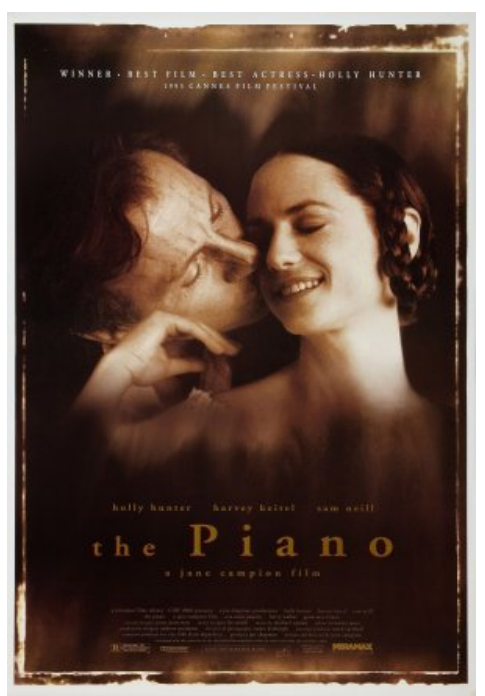

Fig. 1. $<$ A Poster for the film, The Piano $>$

This paper plans to analyze The Piano, focusing on how the story of colonialism is constituted in the film. The Maori/race 
issue is certainly a compelling discourse that gets left out of "feminist" accounts. In terms of our reading The Piano, the representation of the Maori people is ambivalent. While the Piano problematizes the key relationship between the colonizer and the colonized, however, it consolidates the stereotype of the colonized, which has been constructed by the perspective of the White settler. This paper attempts to examine how the film represents these two ambivalent images of the Maori people and their way of life. At the same time, this paper wants to discuss the issue of identity in a postcolonial era with the portrayal of these ambivalent images.

\section{THE REPRESENTATION OF THE MAORI}

The Piano shows the life of the Maori through the category of the nature/civilization binarizm, based on the race. Through the revelation of the differences surrounding the opposition between nature and civilization, the film tries to show what the Maori's way of life is and how they are living. The difference, for example, is mentioned in the scene of the play-within-thefilm. In the scene the Maori are not capable of making a clear distinction between representation and reality. In the middle of the play, a group of Maori men suddenly attack the 'Bluebeard' after mistaking 'representation' for the 'real'. This scene implies the Maori's belief in the mythical world and their respect for the Nature, denied by the ethos of the European Modernity.

Although the director's main intention about the introduction of this episode is exhibited when Stewart severs Ada's finger [3], the director's another intention is related to the criticism on the Western way of thinking. Mistaking representation for reality, for example, is not only in the Maori's consciousness but also in Ada's. After leaving the piano on the shore, she plays a kitchen table like the piano, although it does not make any sound. As Stewart does not understand the authenticity of the Maori, so he never grasps Ada's mind. The film constructs Stewart's position as the opposition of Ada and the Maori. The combination of 'representation' with 'reality' symbolizes both Ada's and the Maori's spiritual innocence as well as the inharmonious relationship between Ada and Stewart. Through this discourse which raises the difference, the film furnishes the consciousness of the Maori to the spectator without the damage of their innocence.

Another discourse that exemplifies the difference between the indigenous and the settler is constructed in the connotations of sexual expression. Unlike the European settler, the Maori easily expose sexual expression without being oppressed by any norm. The Maori's bold and natural expression about sexuality is implicative and evocative because it elicits the problematic of the repression, created by the European cultural codes. Their sexual expression is detected in several scenes. When Baines is in the river with a group of the Maori people, a Maori woman talks about Baines's sexual needs and shows a meaningful smile with the dialogue, 'you need another wife'. As revealed in a Maori woman's dialogue, the Maori people have a polygamy culture in which men can have more than one wife [4]. Since European descendants in New Zealand do not allow polygamy to men, it makes another difference between the Maori people and the European settler. Polygamy may be regarded as a civilized custom and the Western perception reveals a critique of polygamy as oppressive to women or detrimental to (civilized) development [5]. Owing to the fact that Jane Campion, the director of The Piano, never deals with a polygamy custom of the Maori in the entire film, we can seldom write a speculative comment her perspective about polygamy.

This scene also shows that a Maori man, wearing women's robe, watches Baines with a look of eroticism and says to Baines 'I save you' in a sexually suggestive way. It implies that the Maori people normally embrace the homosexual tendency in their community and that the homosexuality may be one of the human instincts. The Maori scorn Stewart with sexual expression, alluding to him as 'old dry balls' for the symbolization of a 'bad' colonist from the start of the film. In another scene, together with a group of Maori children, Flora strokes the trunks of trees with a sexual gesture. This scene clearly reveals a reference for the difference concerning sexual expression between the Maori and the European. The Maori just watch their children' behavior. Stewart, on the contrary, punishes Flora on the ground that this behavior is so bad while she does not understand why it is bad. These scenes show the contrast between the white character's sexual repression and the Maori's natural response to sexuality. Through these references surrounding the differences between the Maori and the settler, the film elicits the discourses of the passion.

The Piano deals with the interaction between the release of latent passion and its repression. However, this interaction is just related to the white characters. The film does not depict the Maori people as human beings who have longing; they are living within the basic instinct of needs and gratification. Their desire is in the frame of human instincts, and is therefore not considered as 'the passion' of the Western notion. The film, therefore, describes the passion as the most principal and original feeling of human nature only within the civilized world. This point is well expressed in the development of the relationship between Ada and Baines.
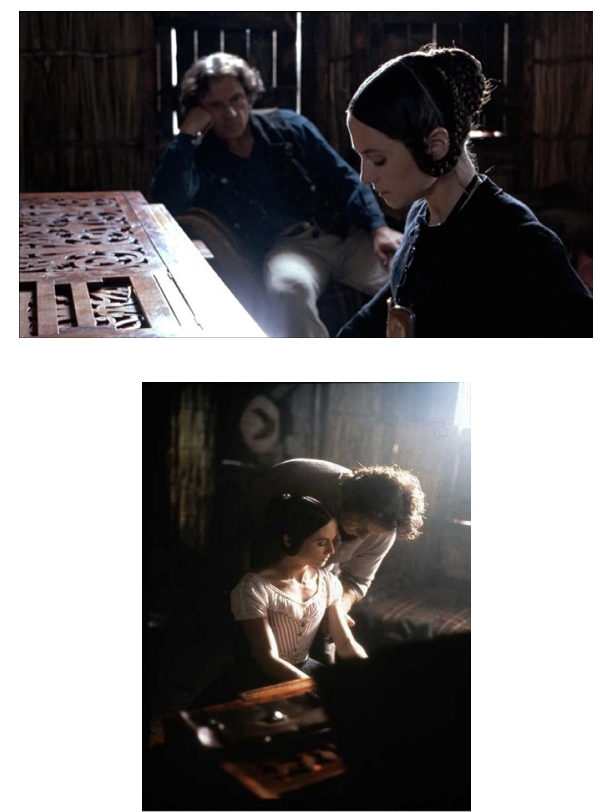

Fig. 2. < pictures of Ada and Baines from piano lesson scenes> 
Their relationship is gradually intensified as the passion becomes too deep for them to control. Ada, a woman of nineteenth-century Victorian period, is an 'elective mute' [6], and communicating with her fingers. Ada is a figure for signifying the repression of passion, controlled by the traditional British values. In one scene, looking at herself in the mirror, she exposes her passion through kissing her reflection. Her sexual desire is the resistance to the repression for the establishment of her own identity. Gillet explains Ada's desire as the expansion of her longing: "She turns from the boarded windows to her own image reflected to her own eyes and so escapes, takes herself through the mirror beyond the houseprison [7]." In another scene Ada touches and caresses Stewart's body when he is between sleep and wake. It symbolizes her active position and his passiveness as a result of her resistance. In Bruzzi's reading, this scene is used for exemplifying "her manipulation" of Stewart [8].

Ada denies her identity as an item of the house, while Stewart tries to possess her through the detention. Here, the viewers see how Stewart regards Ada. Stewart treats Ada as one of his possession. This aspect is clearly displayed when he attempts to rape her. The rape scenes provide us the implication of how the Victorian men consider women in that the rape is possible after the woman is regarded as non-human. Baines also considers Ada as something with exchange values. In the early scenes of the film, Baines treats Ada as a kind of commodity and requires Ada to make a deal between the piano and caress. Ada's passion for her own identity culminates in the last sequence; Ada becomes a newborn entity after plunging herself with the piano in the ocean and then leaving her piano in the water. It shows that her new life emerges from her own resistance and her own selection, not from Stewart's or Baines's. Therefore, Baines can only become "her lover when he realizes ... his domination is not what he wants [9]." Through the resistance against docility, both Baines and Stewart are forced not to consider her as a living doll. At the end of the film, Ada transmits her own voice to the spectator for signifying the establishment of her own identity in the wake of the resistance.

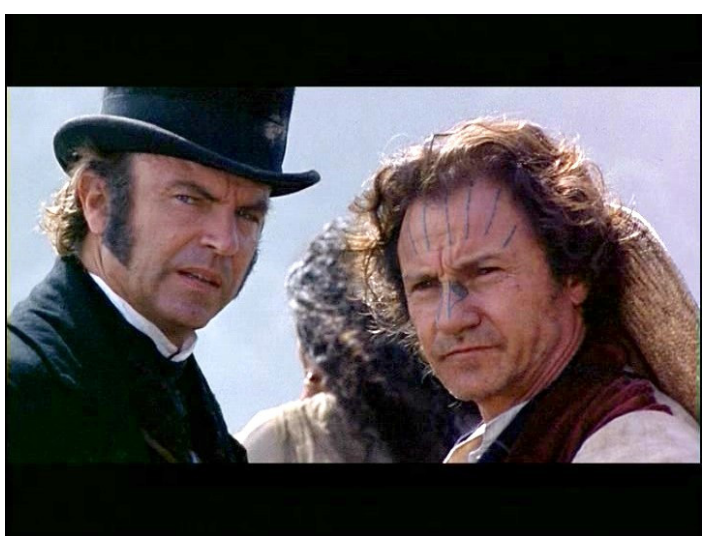

Fig. 3. $<$ Different images between Baines and Stewart $>$

The Piano proceeds to the depiction of the Maori as the independent beings. In the film, the relationship between the indigenous and the settlers is not similar to the relation of the servant to the master. The Maori people have their own voices. They overtly express hostile and disregardful attitudes against the bad settler such as Stewart; they mimic his behavior and scorn him. In one scene their sovereignty is shown when Stewart attempts to negotiate over the land with a group of Maori men. This scene explicitly breaks from the convention of colonial stereotyped images of the indigenous. Stewart, a representative of whiteness, is too impotent to make a deal with the Maori. After the refusal to transact their land with the guns and blankets which have proper exchange values in Stewart's notion, an old Maori man argues 'Never, there is no price you can pay' for the land. In this scene, his dialogue is for all of the spectator in the world. It proposes that there is something that cannot be converted into exchange values.

Through depicting Stewart as a standard colonial settler who cannot completely understand 'the other', Jane Campion seems to tell negative aspects of the colonial self-image. The colonist's self-image is a mirror-image which is reflected from the definition of what the other is. homi bhabha explains the colonist's self-image emerges from the ahistorical nineteenthcentury polarity of Orient and Occident [10]. It "unleashed the exclusionary imperialist ideologies of self and other" in the title of civilization and progress [11]. However, the colonist's selfimage, his/her identity, is required to be transformed in a new situation because of the end of the colonialism [12]. It is clearly displayed in the characterization of Stewart and Baines. In contrast to Stewart who clings to the European tradition, Baines, who seldom follows the British way of life, can speak the Maori's language, and is therefore able to understand the Maori's way of life. The film exposes what New Zealand does need for the reproduction of its identity in a postcolonial world, by providing more emotional affinity to Baines rather than to Stewart. Unlike Dyson's argument, therefore, Baines is not the man who "has already gone native [13]." Similar to my reading of Baines's positioning, Gillett regards Baines as the man who embraces two kinds of living ways: "Baines's tattooed face does mark him as already open at the borders of identity, as touched and altered by the encounter with identities other than that of the colonial master [14]." Jane Campion signifies Baines as the bridge combining the European settler with the Maori. Baines shows commitment to the Maori's way of life. But he is always prepared to take the British way of life because of never losing it. It is well revealed in the last scene of the film. Baines takes the British way of life in his and Ada's house of the Nelson, while he abandons the Maori's way of life. Nevertheless, Baines seems to have the ability to understand the Maori in their way. The film, I think, describes Baines as a symbol for the reproduction of a new identity for New Zealand.

The Piano presents positive images of the Maori people to the spectator. On the contrary, the film also constructs negative images of them. This ambivalence is a result of multiple encodings, whether they are intended by the director or not. Through transmitting stereotyped images of the indigenous, the film encourages the reproduction of marginal images of the Maori. It is partially reveals in the metaphor of whiteness as purity. In the film whiteness symbolizes purity, cleanliness and spiritual innocence. As Dyson argues, the symbolization of whiteness "recurs throughout the film [15]." Dyson elicits an example of this metaphor from the second beach-scene. In this scene a Maori woman describes Ada as 'she looks like an angel'. The dilemma is how to read this exclamation. I am unable to 
explain where the Maori have the image of an angel and what it means. The episode concerning this exclamation, I think, is a typical illustration of the colonial eyes. According to the narrative of the film, any Maori woman never becomes an angel with the image of whiteness. By using the Maori's voice, furthermore, the film presents Ada with the image of an angel. This is a pattern which shows how the European describes the indigenous in the colonist's way.

Whiteness is also used as a mode for fortifying Ada's sexuality. The revelation of Baines's sexual desire toward her begins with whiteness disclosed in her bared shoulder and neck. Before Baines touches and kisses her neck, the camera, considered as Baines's glance, shows Ada's white neck when Ada is playing the piano. Unlike Ada with erotic images of whiteness, Maori women are represented as the desexualized. The film reinforces Ada's purity and eroticism by the racial difference. The Maori women are physically unrefined and crude as opposed to the definition of the 'erotic'. This point is found in Dyson's reading: "While the eroticized image of Ada appears translucent and free from blemish, the Maori women are physically desexualized through their representation as lank-haired, toothless and devoid of the conventional markers of femininity [16]." Two white women, house servants, are also desexualized, however, they do not involve the connotation of sexuality in the film. Unlike white house servants, the Maori women are involved in sexual implication. In one scene when Flora is crying in Baines's house with Ada's severed finger, Baines enters into his house with a Maori woman who told him 'you need another wife' in the river scene. Here is that their sexual relation is implied. The spectator already discerns their closeness when she serves him with food. In this scene, she sits at the table while Baines yells out 'Leave. Go on. Go' toward Ada. These three scenes, for me, imply sexual relationship between Baines and a Maori woman. This is not explicitly expressed in the film, but is certainly implied. The question is how we can figure out it and read hidden meaning of this relation. Their relationship is connected with the contrast between the European's passion and the Maori's instinct of needs. Theirs follows the instinct of needs, which does not pursue the meaning of possession.

The connotation of this relationship is sexual needs. However, the more important implication is that it is used for Baines's positioning between the European's and the Maori's way of life. The revelation of the difference between the settler and the indigenous is applied as the backdrop for the authenticity of the relationship between Ada and Baines. He is characterized as the mixture of the European and the Maori. However, Baines's cultural positioning is confused by Ada's appearance. He is almost certainly living in a way in which the Maori are doing, without the involvement with the passion which is created by the civilization. He experiences the desire because of Ada and expresses it to Ada in some strange ways, closer to sexual harassment. The discussions about sexual relations between Ada and Baines are clearly shown in two different positions. Gillett emphasizes that sexual relations between Ada and Baines in the early scenes cannot be read by the terms such as 'sexual harassment' or 'rape'. John Spooner, on the contrary, views these relations as 'sexual harassment', while criticizing the way by which Baines only looks good [17].
Baines expresses his passion in the dialogue when Ada comes to his house after taking back the piano: '. . . Ada, I am unhappy because. . . I want you, because my mind has seized on you and can think of nothing else. This is why I suffer. I am sick with longing'. He recovers the passion that is hidden beneath the nature's way of life after Ada's appearance.

Baines tries to forget Ada and discard his passion toward Ada, and, hence, he makes a decision not to possess the piano, which is considered Ada herself. In the scene when Ada comes to Baines's house after watching the movement of the piano from Baines's house, Baines tells her: '. . . I want you to care for me, but you can't ... It's yours. Leave. Go on. Go'. Baines stays with a Maori woman, who cooks for him, in the house at the moment when He tries to go back to the Maori's way of life, hiding his desire. The dilemma with reading The Piano through the discourses about the sexual connotation between Baines and a Maori woman is that it is extremely difficult to understand and explicate a different dimension of sexual relationship between men and women. This sexual relationship results from human instinct of needs and its active acceptance, a fundamental and primal element of the Maori cultures. It cannot be understood within the framework of the civilized culture, therefore, should not be evaluated from only the Western perspective. Nevertheless, Pihama, a Maori woman, reveals her wrath after watching The Piano. For her, the implication of sexual relationship between them means that Maori women available at all times to service the Pakeha men, whether she is sexualized or desexualized. Pihama regards The Piano as a dangerous movie to the Maori because this film proliferates stereotyped images of them [18].

Throughout the film, the Maori women are depicted as house servants. They are not slaves, but servants. They work for Stewart who orders them to follow some of the British way of life. They cook for Baines. In addition to that, the Maori men function as laborers for the white settler. We cannot know why they work for the settler and what they get from the service because the film does not include the explanation for that. Like a natural phenomenon, the Maori are described as servants. At the early scene and closing scene of the film, the Maori people are assigned to carry Ada's belongings. Any white man does not move her stuffs. The film does not imply any reason why they do it. They seem to be considered as the men who like enjoying the work and cooperation, although they hate Stewart. The Maori people are represented as laborers and servants for the European settler in the film, no matter what reason the film provides.

It cannot be denied that images of the Maori are controlled by the colonial perspective in the film. As revealed in the credit of the film, Jane Campion employs a Maori cultural advisor for the appropriate revision of the story because she wants to describe the Maori people as real as she can. Dyson emphasizes the employment of a Maori advisor as a proper method for the establishment of the reconciliation: "The use of 'cultural advisor' to guarantee the authenticity of the Maori reinforces the discourses of primitivism in the film which construct the indigenous people as the repository of unchanging traditional values - in harmony with nature, childlike - the textual echo of all that has been lost [19]." In an interview, Jane Campion tells her opinion in line with Dyson's interpretation: "I had not 
expected people saying how good I understood them. I believe that my original plot was more like a cliché. I wished to protect the Maoris in the film and I was sure that I showed their right spirit [20]." Jane Campion attempts to disclose the Maori's spiritual innocence, but she just emphasizes that they are not children, although they are naive and childlike. For her, it is transformed as a central motif in the story of the colonialism.

Jane Campion uses sexual harassment, transaction of the piano with caress and authentic love for the depiction of the relationship between Ada and Baines. As Jane Campion shows all the subtle messages manifested in the development of the relationship between Ada and Baines, so she shows all the sophisticate messages concerning images of the Maori. The question surrounding whether the story of the colonialism is constructed as real and plain as possible are not only in the director's hands. These questions depend on the spectator's reading after the production of a film ends. The more important is how the spectator reads The Piano and interprets images of the Maori and their way of life. The Piano does not expose the viewer to one-dimensional messages regarding the 'naive but nevertheless noble savage's life and culture. The viewer, therefore, obtains all of ambivalent images about the Maori people and their way of life. It is because the film is composed of the intricate and paradoxical messages about them: The Maori people respect the nature and live in a harmony with their environment. They are protestants and denier against the colonists and their way of life. However, the Maori are laborers for the settler. They are servants for cooking and others.

\section{CONCLUSION}

In the film, the most overt ambivalence is clearly shown in two images of the Maori, at once 'naive but nonetheless noble' and 'inferior'. On the one hand, the film shows the Maori people enjoying freedom without any restraint and living in harmony with nature; on the other, the film shows the Maori people as inferior servants for the European settlers. The film reveals the differences between the Maori and the dominant white settler, and positive aspects of the Maori's way of life. At the same time, however, the film reproduces stereotyped images of the Maori people, constructed in the colonial period. The film portrays distorted images of the Maori by the colonial perspective and encourages the marginalization of the Maori through the symbolization of whiteness as purity.

In my view, Dyson's reading of the reconciliation is a reflection which is pursued by New Zealand white settlers for the establishment of a new national identity. It is because this reconciliation is based on partial understanding of the Maori people and their way of life. The reconciliation cannot be accomplished by partial understanding. Partial understanding establishes just incomplete reconciliation between the Maori and the Pakeha. Although the Pakeha already throw away the notion of superiority that the European acquired in the colonial era, they are still outsiders to the Maori people. Like any indigenous people of the ex-colony, the Maori people are still living in a postcolonial world after the colonial period ends. The Pakeha, descendants of the European, endeavor to establish a new national identity with the Maori, but the conflict between them still exists both because the Pakeha do not completely consider the Maori as the partner with the equal qualification, and because they do not entirely abandon the ideological and cultural legacy regarded as the remnants of the colonialism. In my view, Jane Campion maintains her perspective within the confines of partial reconciliation. The Maori people are produced as 'the other' within her text, although she attempts to depict the Maori as real as possible and not to spoil the authenticity of the Maori people.

As analyzed in this paper, The Piano describes the differences between the Maori people and the European settler. The questions are how these differences are constituted in the film and how the film represents the Maori. Through the revelation of these differences, the film provides the spectator with ambivalent images of the Maori people. By the depiction of these ambivalent images, any Maori person is required to get two kinds of oppositional identities, no matter what authentic identity he/she has. On the one hand, the Maori people become 'naive but nevertheless noble'; on the other hand, they become 'inferior' servants. The establishment of their own images does not need their consent. They do not have a chance to make their own identity. Besides, the continuation of distorted and stereotyped images of the Maori people, constructed by the colonial gaze, demonstrates that they are living in a postcolonial world, even though they are in the world in which the end of colonialism is already celebrated.

\section{REFERENCES}

[1] L. Dyson, "The return of the repressed? Whiteness, femininity and colonialism in The Piano," Screen, vol. 36, no. 3 , 1995, p. 267.

[2] L. Dyson, "The return of the repressed? Whiteness, femininity and colonialism in The Piano," Screen, vol. 36, no. 3, 1995, p. 268.

[3] S. Gordon, "I clipped your wing, that's all: auto-eroticism and the female spectator in The Piano debate," Screen, vol. 37, no. 2, 1996, pp. 200-201.

[4] N. Seuffert, "Shaping the Modern Nation: Colonial Marriage Law, Polygamy and Concubinage in Aotearoa New Zealand," Law Text Culture, vol. 7, no. 1, 2003, pp. 186-220.

[5] M. K. Zeitzen, Polygamy: A Cross-Cultural Analysis. New York: Berg, In this book, the author emphasizes that polygamy is not just an non-Western practice, but also exists in modern Western societies, 2008.

[6] S. Bruzzi, "Tempestuous petticoats: costume and desire in The Piano," Screen, vol. 36, no. 3, 1995, p. 265.

[7] S. Gillett, "Lips and fingers: Jane Campion's The Piano," Screen, vol. 36, no. 3, 1995, p. 278.

[8] S. Bruzzi, "Tempestuous petticoats: costume and desire in The Piano," Screen, vol. 36, no. 3, 1995, p. 261.

[9] S. Gillett, "Lips and fingers: Jane Campion's The Piano," Screen, vol. 36, no. 3, 1995, p. 282.

[10] h. k. bhabha, The location of culture, London \& New York: Routledge, 1994.

[11] h. k. bhabha, The location of culture, London \& New York: Routledge, 1994, p. 19. 
[12] Arif Dirlik includes the discussion about the crisis of the European identity in a postcolonial society in his article; see A. Dirlik, "The Postcolonial Aura: Third World Criticism in the Age of Global Capitalism," Critical Inquiry, vol. 20, no.4, 1994, pp. 328-356.

[13] L. Dyson, "The return of the repressed? Whiteness, femininity and colonialism in The Piano," Screen, vol. 36, no. 3,1995, p. 268.

[14] S. Gillett, "Lips and fingers: Jane Campion's The Piano," Screen, vol. 36, no. 3, 1995, p. 283.

[15] S. Gillett, "Lips and fingers: Jane Campion's The Piano," Screen, vol. 36, no. 3, 1995, p. 272.

[16] S. Gillett, "Lips and fingers: Jane Campion's The Piano," Screen, vol. 36, no. 3, 1995, p. 271.

[17] S. Gillett, "Lips and fingers: Jane Campion's The Piano," Screen, vol. 36, no. 3, 1995, p. 285.

[18] L. Pihama, "What counts as difference and what differences count: gender, race and the politics of difference," in Johnston, Patricia \& Pihama, Leonie (1995), The Worlds of Maori Women. Auckland: Penguin Books, 1995, p. 240.

[19] L. Dyson, "The return of the repressed? Whiteness, femininity and colonialism in The Piano," Screen, vol. 36, no. 3,1995 , p. 275.

[20] Helen Barlow, "Interview with Jane Campion", http://www.ifi.uio.no/ magnush/Piano/campion.html (accessed 10 August 2005).

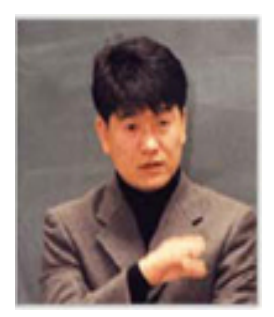

\section{Seung Hyun Park}

$\mathrm{He}$ is a professor in School of Communications at Hallym University. His current research mainly deals with the film industry and its performance.

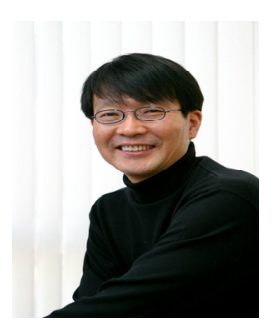

\section{Jae Il Nam}

$\mathrm{He}$ is an assistant professor in the Department of Journalism and Mass Communication at Kyungpook University. His research interests are central to cultural implications in journalism. 